\title{
Developing coaching skills of managers in global context
}

\author{
Peter Seemann ${ }^{1, *}$, Zuzana Stofkova ${ }^{1}$, and Vladimira Binasova ${ }^{2}$ \\ ${ }^{1}$ University of Zilina, The Faculty of Operation and Economics of Transport and Communications, \\ Univerzitna 1, 01026 Zilina, Slovak Republic \\ ${ }^{2}$ University of Zilina, The Faculty of Mechanical Engineering, Univerzitna 1, 01026 Zilina, Slovak \\ Republic
}

\begin{abstract}
Globalization leads to a more connected world with farreaching impact on production arrangements, international trade, foreign investment and economic growth. This paper deals with the application of coaching skills of managers in a global context, which influences the style of managerial leadership after completing their development courses. Managers use different styles of leadership, but they give people more space and self-realization than to manage them in a directive-based and order-based manner. These reasons support innovation and creative thinking of employees. The first section focuses on specific management styles, methods of employee education and development and survey of the literature. The case study in selected company deals with the survey, the subsequent evaluation of the exploratory results and the expression of proposals and recommendations. The results showed that the implementation of coaching positively affects not only the managerial style but also the whole company. For managers, interest in their people has grown and a new corporate culture has emerged in many companies. Responses of managers show that they are more likely to handle tense situations, smaller groups, seek solutions, and give employees more space. With the coaching approach, they are relieved of routine problems and have more trust in subordinates.
\end{abstract}

\section{Introduction}

Coaching is a creative process that inspires employees to reach their maximum potential. In leadership, it is necessary to separate implementation and decision-making competences. This means that one person in the company devises and twenty people work on these ideas. Problems are usually solved not at the levels at which they arose, which can cause cost and time and can also lead to the loss of substantial data between levels. Employees usually do only what is in their job description. In practice, there are a large number of methods for training and developing employees and executives. These methods are divided into aspects according to the company direction, form and number of participants and the location of the training (Fig. 1).

* Corresponding author: peter.seemann@fpedas.uniza.sk 


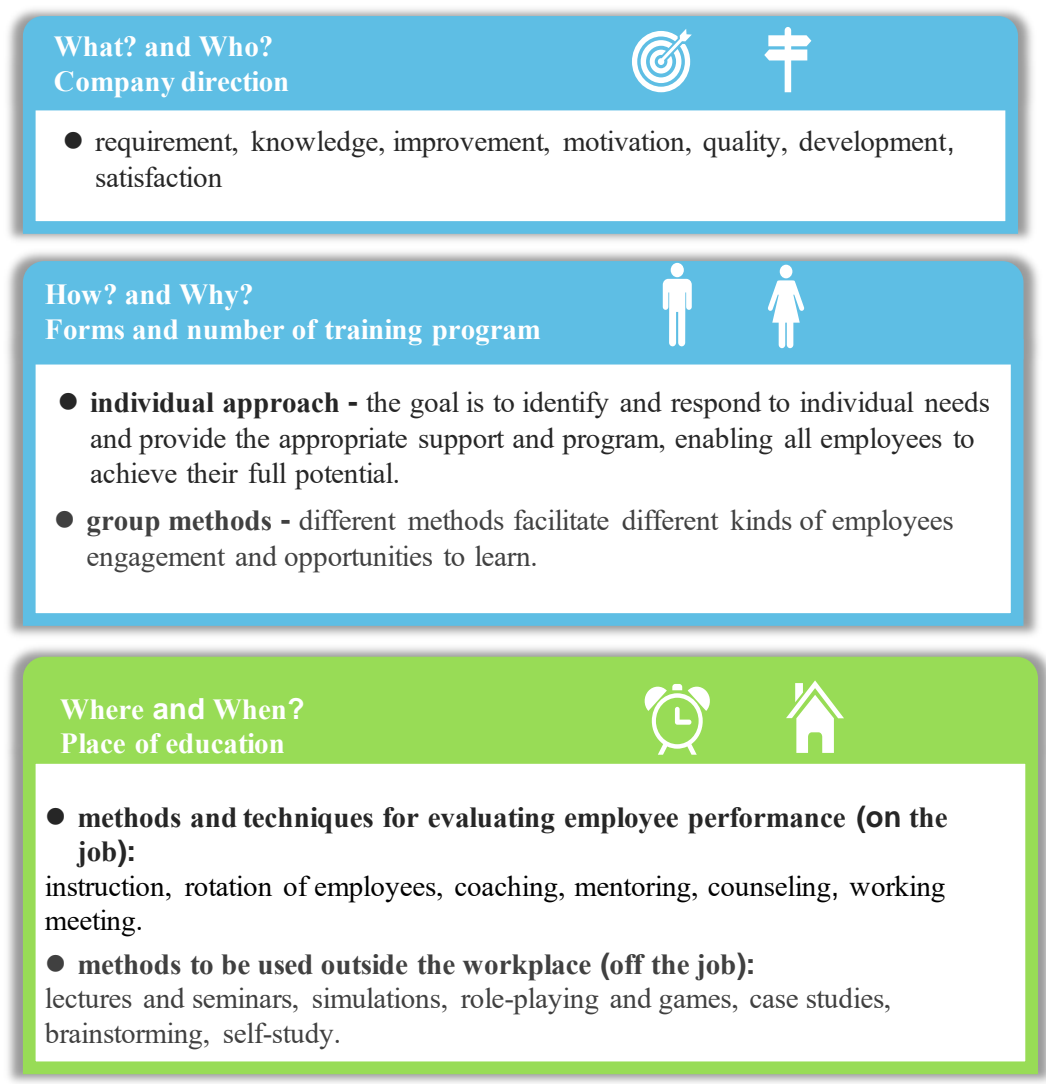

Fig. 1. Methods for training and developing employees and executives.

According to [1], who examined the impact of training on the development and promotion of the use of coaching skills on individual and corporate behaviour, it was found that by training individuals in coaching skills it is possible to improve the skills needed to work together and solve problems jointly. This training programme enabled the development of skills and understanding such that those who agreed to contribute to the evaluation said that they developed their abilities to listen more effectively and to ask better questions. An in-house coaching training program can solve a variety of organizational issues and allow progress in addressing these issues.

\subsection{Manager as a coach}

Most successful managers coach their subordinates so that they sometimes do not even realize it. The manager does not make full use of coaching as an experienced coach, but only certain elements of it. He can guide his people in different ways and must, therefore, choose the way that will be most effective in that particular situation. It is therefore advisable to combine coaching with other methods of leadership. He uses coaching in situations where it makes sense. Many managers attend courses where they learn the entire coaching process. As a coach, the manager invests his time in his staff to develop their confidence in the performance of new tasks and engages them in the development of strategic plans. It seeks to use those principles of coaching that contribute to the 
achievement of business goals. It is very important to build a partnership with your subordinates.

Managerial coaching (also known as the leader-as-coach model) is becoming prevalent as a new management paradigm to develop and empower employees and help them increase their performance. At the same time, the composition of the workforce has changed, with female employees reaching almost $50 \%$ of workers and around $30 \%$ of managers. Accordingly, scholars have set out to understand if gender affects managerial behaviours and employee responses. The goal of the study, [2] is to evaluate if significant differences in performance should be expected when coaching female and male employees. Managerial coaching positively affects female behavioural and result performance and male behavioural performance, but - contrary to expectations - no significant effect was found for coaching on male result performance. Additionally, female and male employees differ in their self-evaluation of the focal performance constructs, with females evaluating their contribution to performance at lower levels than their male counterparts. The results suggest that to be an effective developmental tool, the approach taken with coaching should take into consideration the recipient's gender and address different areas of performance.

[3] suggest that ongoing coaching from one's manager is critical for performance management because it facilitates the process of providing feedback, setting goals, and monitoring progress toward those goals. As such, coaching is inextricably linked to the feedback process and more specifically, feedback from one's own manager. Although feedback is commonly noted as being part of coaching [4-6], it was only recently that [7] developed a model of feedback for the executive coaching paradigm. This model specifically highlights the role of the coach as the feedback source and suggests the coachee's receptivity to feedback is a critical lynchpin in the process.

[8] define the manager-as-coach process as a "developmental activity in which an employee works one-on-one with his or her direct manager to improve current job performance and enhance his or her capabilities for future roles and/or challenges, the success of which is based on the relationship between the employee and manager, as well as the use of objective information, such as feedback, performance data, or assessments.

Currently, there is a trend in organizations to reduce reliance on once-a-year performance appraisal and promote ongoing manager feedback and coaching [9]. The study [10] has a number of implications for managers and organizations interested in moving in this direction and enhancing the manager-as-coach process. Organizations can help increase a manager's awareness of the indicators of coaching effectiveness, coaching behaviours, the coaching relationship, and the feedback environment.

Managerial coaching is currently seen as an effective leadership practice facilitating the learning process of the employees for performing better and being more effective in organizations. The study [11] used a pre-post-test approach to test the effects of the coaching program specially designed for 23 mid-level managers having as responsibility the supervision of production teams in a multinational organization. The major aims of the program consisted of developing managerial coaching skills, assertive communication skills, the motivation of subordinates. Overall, the analysis of results elicited an increase of scores in the leadership behaviour dimensions measured by the multifactor leadership questionnaire that are part of the managerial coaching skills. Besides, the effectiveness perceived as an indicator of performance was significantly higher upon completion of the coaching program. Findings suggest that coaching, as a professional development method, has great potential to contribute to the managerial behaviours that facilitate development at the subordinate level, as they are captured by some transformational and transactional scales. Team reflection turned out to be a moderator and not a mediator in the relationship between managerial coaching and team performance. Only the performance of poorly reflective teams benefits from managerial coaching [11]. 


\section{Methods}

The main objective of the next chapter is to compare how managers have led their people before acquiring coaching skills and how their leadership style has changed after acquiring these skills. To determine the results, we used a questionnaire survey, which was completed by managers who took a course to develop coaching skills. We've used the following research questions to try to confirm or refute based on the results:

1. We assume that the style of leadership has changed from a directive to a democratic one.

2. We assume that managers use at least 3 coaching skills after the course.

3. We assume that managers are interested in using and developing coaching skills after the course.

The following methods were chosen for the study. Focus group as a qualitative research method consisting of a group of people. They will meet at a specified place and at a specific time and during this meeting, the moderator will gradually ask questions about the topic that we have prepared in advance. Respondents respond to questions and discuss. At these meetings, opportunities to improve the application of coaching in the workplace after a course to develop coaching skills were discussed. Participating managers who attended this course commented on this issue.

Furthermore, we have compiled a questionnaire, which we have filled out the managers participating in the focus group meetings. It consisted of 8 questions, of which 3 were open, where managers wrote their views on the questions and a further 5 demographic questions to find general information about respondents. Through this exploration probe, we found that creating a survey makes sense. The questions are divided into three areas:

- Management style before acquiring coaching skills.

- Using coaching skills in post-course driving.

- Management style after acquiring coaching skills.

The current studies address this gap by examining the role of one coaching manager characteristic, feedback orientation in the coaching process. In particular, we draw on frameworks for the manager-as-coach process [11-13] and feedback processes within a general coaching framework $[7,14]$ to examine the impact of manager feedback orientation on employees' perceptions of the coaching process including effective coaching behaviours, development of a quality coaching relationship, and facilitation of a favourable feedback environment. Employee motivation can work effectively only if it is based on adequate knowledge and understanding of motivation factors and their differentiation in relation to certain types of employees $[15,16]$. We also examine the extent to which manager feedback orientation may be related to employee feedback orientation and if this relationship is mediated by coaching behaviours, coaching relationship, and feedback environment. Fig. 2 depicts this theoretical model.

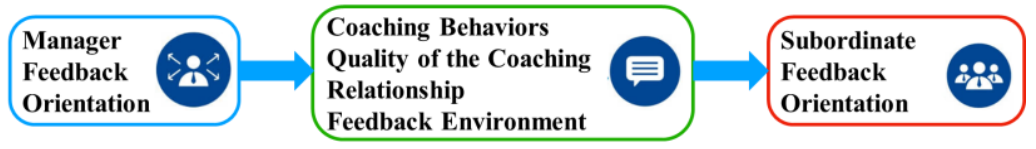

Fig. 2. Model of the role of feedback orientation in the manager-as-coach process [10].

The understanding and interpreting of voice have gained significant recognition among practitioners and researchers in recent years [17,18]. Very interesting are the results of research [19]. They indicate that neither coaching scale is perfectly reliable and valid. However, given the results of the analysis, the authors recommend the Park scale for leaders and the Ellinger scale for team members.

[20] propose that the presence of relationship conflict in even a single dyad within a team can hinder information exchange, whereas the level of information exchange in teams 
can unlock task conflict. We argue that task and relationship conflict, due to this unfolding process, shift from an initially significant positive relationship to a null relationship over time. Based on related literature [20-24] such as mentoring, career success, 360-degree feedback, and training and development, the important constructs in the process are coaching approach, the relationship between the coach and the coachee, and the feedback receptivity of the coachee.

\section{Results}

The questionnaire was completed by 15 respondents, including 10 men $(66.7 \%)$ and 5 women $(33.3 \%)$. The largest part of respondents is from the IT sector 3 managers $(20 \%)$ and from the field of mechanical engineering also 3 managers $(20 \%)$. Other respondents were in the insurance $(6.7 \%)$, consulting $(6.7 \%)$, tourism $(6.7 \%)$ and telecommunications $(6.7 \%)$. In the field of education, there were 2 managers $(13.3 \%)$ as well as 2 managers (13.3\%) from sports management.

Within this part of the questionnaire, respondents also answered the open question: "What aroused your interest in coaching?". The managers replied that they wanted to develop in their leadership as well as in personal development, they needed to try something new, wanted to learn what coaching could be useful for them, they wanted to use coaching as a new problem-solving tool. They took a course to get closer to people, but also because of the need to constantly improve and educate.

After completing the course, managers use mainly active listening, which was indicated in the questionnaire by 14 respondents. The second most commonly used skill is to ask important questions (11) and to rank the third in establishing proximity and trust with employees, direct communication and planning and goal setting. Possitive changes after after using coaching in leadership are shown in Fig. 3.

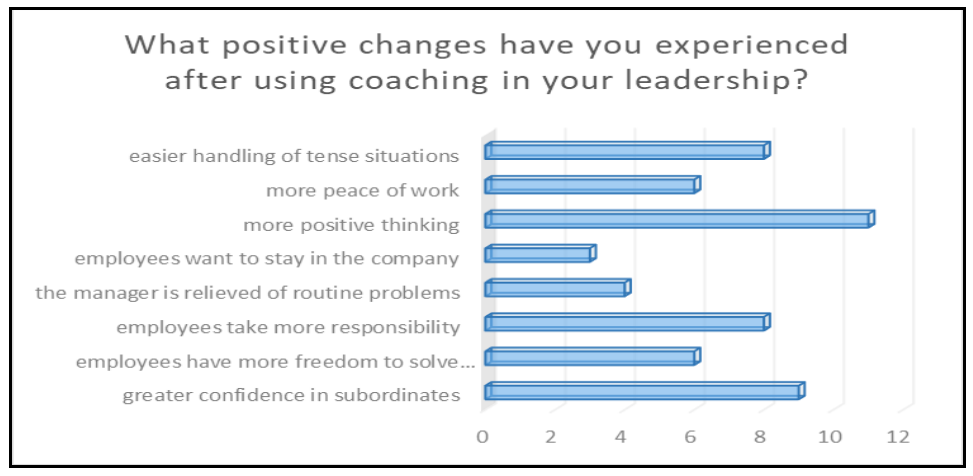

Fig. 3. Positive changes after using coaching in leadership.

To the question "What opportunities do you use them?" Most managers answered that with colleagues at work, suppliers, home, family, annual reports of subordinates, problematic situations in the company, solving problems with employees whenever people are not aware of something. Out of a total of 15 respondents, 7 managers use coaching skills 2-3 times a week in their leadership. Only 1 respondent said they rarely used coaching skills. Out of a total of 15 respondents, 7 managers use coaching skills 2-3 times a week in their leadership. Only 1 respondent said they rarely used coaching skills.

Most managers (9 respondents) who have completed a coaching skills development course are interested in continuing to develop in the field. Only one respondent out of the 
total claims that they probably do not want to develop further in this area. No respondent responded that they would certainly not develop in their coaching skills.

\section{Discussion}

In this section, we will discuss the above results. As already mentioned, the questions in the questionnaire were divided into three parts.

In the first part of the questionnaire, which focused on leadership style before acquiring coaching skills, we came to the conclusion that most respondents who participated in the survey led their people in a directive manner. They required their employees to fulfil their orders unconditionally. They communicated with them from top to bottom, which meant that they were ordering them and expecting them to be fulfilled. They were motivated by rewards and verbal appraisal or did not feel the need to reward them, and it was most important for managers to ensure that their subordinates performed their assigned tasks independently. Conflicts that have arisen in the workplace have been resolved through the use of their status and powers. The reason for managers to take a coaching skills development course was mainly the need and interest to develop in their leadership, the desire to get closer to people, the need to try something new and wanted to learn how coaching could be useful to them. The second part of the questionnaire focused on the use of coaching skills in post-course management. Respondents said they mostly used active listening and asking important questions in their leadership. They use coaching skills especially with colleagues at work, with suppliers, at home with the family, but also mainly in communicating with employees such as problem-solving, problematic situations and annual subordinate evaluations. Most respondents use them 2-3 times a week. Most of them expressed their interest in continuing to develop their coaching skills.

In the last part of the questionnaire, which included questions about leadership style after acquiring coaching skills, all respondents stated that they had experienced the following positive changes after completing the course and integrating coaching skills into their leadership style. Managers have the ability to think more positively. They feel more confident about their subordinates, easier to cope with tense situations and employees take on more responsibility. Managers give their employees more freedom to resolve conflicts and thus feel more at ease at work. Based on the results of the survey, we can conclude that the development of coaching skills of managers and their application to the management style positively influences not only managers but also employees of the company.

At the beginning of the practical part we have identified 3 exploratory areas, which according to the previous results we evaluate as follows:

1. We assume that the style of leadership has changed from a directive to a democratic one. According to the results of the survey, it is clear that managers were leading their people in a more direct way before acquiring coaching skills. After completing a coaching skills development course, there were positive changes in their leadership style, which suggests that their leadership style has changed rather too democratic. Therefore, we can confirm this assumption.

2. We assume that managers use at least 3 coaching skills after the course. Based on the second part of the questionnaire, we also confirm the second assumption, because the respondents clearly stated that they use at least 3 coaching skills 2-3 times a week.

3. We assume that managers are interested in using and developing coaching skills after the course. We examined this assumption in the second part of the questionnaire, where respondents were asked to comment on the question? "Are you interested in continuing to develop your coaching skills?" The answers clearly show that most respondents are interested in developing their coaching skills after the course. We can, therefore, confirm the third assumption. 


\section{Conclusions}

Based on the results of the survey, we concluded that coaching courses are very important for the professional as well as personal development of the manager as well as for the successful running of the company. Therefore, it can be argued that participation in courses designed to develop coaching skills is very beneficial. Therefore, we would like to recommend managers in all areas of the business to attend the courses. This will bring them many positive changes, especially regarding access to employees. Managers will be more interested in their people, which will also generate interest from employees. It is an investment in the development of human resources, which will be returned several times in making work and organization more efficient. This is manifested in the increased initiative, employee responsibility and lightening of the manager's workload. For the organizers of these courses, we would recommend more time to devote the work of managers with their own attitude towards the subordinates. Changing the attitude of the manager is crucial for changing the style of management, increasing trust and unlocking the potential and responsibility of the subordinates. In addition, we would recommend introducing more "minute interviews" into the courses, which are of great benefit in building a relationship with employees. These are short, often informal, managerial interviews aimed at solving the problem or just briefing the employee. However, they include the use of coaching skills (active listening, effective questions, sometimes the growing process) and are a very practical and effective managerial coaching tool. We would also like to recommend that company employees be coached by their superiors (managers) and be open to new coaching opportunities. If employees are not willing to be coached, coaching by the supervisor is meaningless.

This paper is an output of the science project KEGA 043ŽU-4/2019, VEGA 1/0755/18.

\section{References}

1. G. Boak, S. Crabbe, Evaluating the impact of coaching skills training on individual and corporate behaviour. European journal of training and development 43, 153-165, (2019)

2. C. Pousa, D. Richards, C. Trepanier, Managerial coaching of frontline employees: The moderating role of gender. Human resource development quarterly 29, 219-241, (2018)

3. J. B. Gregory, P. E. Levy, Coaching in a performance management context: A review and research agenda. Paper presented at the annual conference of the Society for Industrial and Organizational Psychology, (2009)

4. D. C. Feldman, Career coaching: What HR professionals and managers need to know. Human Resource Planning 24, 26-35 (2001)

5. B. Joo, Executive coaching: A conceptual framework from an integrative review of practice and research. Human Resource Development Review 4, 462-488 (2005)

6. R. R. Kilburg, Toward a conceptual understanding and definition of executive coaching. Consulting Psychology Journal: Practice and Research 48, 134-144 (1996)

7. J. B. Gregory, P. E. Levy, M. Jeffers, Development of a model of the feedback process within executive coaching. Consulting Psychology Journal: Practice and Research 60, 42-56 (2008) 
8. J. B. Gregory, P. E. Levy, Employee coaching relationships: Enhancing construct clarity and measurement. Coaching: An International Journal of Theory, Research and Practice 3, 109-123 (2010)

9. E. D. Pulakos, R. Mueller Hanson, S. Arad, N. Moye, Performance management can be fixed: An on-the-job experiential learning approach for complex behavior change. Industrial and Organizational Psychology 8, 51-76 (2015)

10. L. A. Steelman, L. Wolfeld, The Manager as Coach: The Role of Feedback Orientation. Journal of business and psychology 33, 41-53 (2018)

11. L. Ratiu, O. David, A. Baban, Developing Managerial Skills Through Coaching: Efficacy of a Cognitive-Behavioral Coaching Program. Journal of rational-emotive and cognitive-behavior therapy 35, 88-110 (2017)

12. M. Buljac-samardzic, M. Van Woerkom, Can managers coach their teams too much?, Journal of managerial psychology 30, 280-296 (2015)

13. J. M. Hunt, J. R. Weintraub, The coaching manager: Developing top business talent. (Thousand Oaks: Sage, USA, 2011)

14. M. London, J. W. Smither, Feedback orientation, feedback culture, and the longitudinal performance management process. Human Resource Management Review 12, 81-100 (2002)

15. M. Hitka, S. Lorincova, M. Gejdos, K. Klaric, D. Weberová, Management Approach of White-collar Employees Forest Enterprises, BioResources 14, 5488-5505 (2019)

16. V. Farkasova, L. Lizbetinova, Kariera ako sucast rozvoja osobnosti. (EDIS, Zilina. 2016)

17. D. H. Celoria, Coaching from the coaches' perspective: aprocess-oriented focus. International Journal of Mentoring and Coaching in Education 3, $72-85$ (2014)

18. A. Ganjali, S. Rezaee, Linking perceived employee voice and creativity. Iranian Journal of Management Studies 9, 175-191 (2016)

19. H. S, Hagen, S. L. Peterson, Measuring coaching: Behavioral and skill-based managerial coaching scale. Journal of Management Development 34, 114-133 (2015)

20. S. E. Humphrey, F. Aime, L. Cushenbery, A. D. Hill, J. Fairchild, Team conflict dynamics: Implications of a dyadic view of conflict for team performance. Organizational Behavior and Human Decision Processes 142, 58-70 (2017)

21. B. K. Joo, Executive coaching: A conceptual framework from an integrative review of practice and research. Human Resource Development Review 4, 462-488 (2005)

22. M. A, Manas, P. Diaz-Funez, V. Pecino, R. Lopez-Liria, D. Padilla, J. M. AguilarParra, Consequences of Team Job Demands: Role Ambiguity Climate, Affective Engagement, and Extra-Role Performance. Frontiers in psychology 8, (2018)

23. I. Markus, Efficacy of immunity-to-change coaching for leadership development. The Journal of Applied Behavioral Science 52, 215-230 (2016)

24. J. Medland, M. Stern, Coaching as a successful strategy for advancing new manager competency and performance. Journal for Nurses in Professional Development 25, 141-147 (2009) 